Review began 01/21/2022 Review ended 01/31/2022 Published 02/01/2022

๑) Copyright 2022

Oyake et al. This is an open access article distributed under the terms of the Creative Commons Attribution License CC-BY 4.0. which permits unrestricted use, distribution, and reproduction in any medium, provided the original author and source are credited.

\section{Airway Emergencies Due to Anterior Mediastinal T-Lymphoblastic Lymphoma Managed With Planned Extracorporeal Membrane Oxygenation and Endotracheal Stent: A Case Report and Literature Review}

\author{
Momoko Oyake $^{1}$, Souichi Suenobu ${ }^{2}$, Michiyo Miyawaki ${ }^{3}$, Yoshifumi Ohchi ${ }^{4}$, Kenji Ihara ${ }^{1}$ \\ 1. Department of Pediatrics, Oita University Faculty of Medicine, Yufu, JPN 2. Division of General Pediatrics and \\ Emergency Medicine, Department of Pediatrics, Oita University Faculty of Medicine, Yufu, JPN 3. Department of \\ Thoracic and Breast Surgery, Oita University Faculty of Medicine, Yufu, JPN 4. Department of Anesthesiology and \\ Intensive Care, Oita University Faculty of Medicine, Yufu, JPN
}

Corresponding author: Momoko Oyake, momoko-oyake@oita-u.ac.jp

\begin{abstract}
Anterior mediastinal tumors can occasionally cause acute respiratory failure by compressing the trachea and bronchi. In such cases, sedative muscle relaxants during tracheal intubation can cause fatal complete tracheal obstruction. We encountered a 15-year-old male patient with T-lymphoblastic lymphoma (T-LBL) of the anterior mediastinum. For his airway emergency due to the stenosis extended from the lower part of the trachea to the tracheal bifurcation, venovenous (VV) extracorporeal membrane oxygenation (ECMO) was introduced from the femoral vein under local anesthesia. After a short period of tracheal intubation management, an endotracheal stent (ES) was immediately placed in the lower trachea. We performed a needle biopsy, and he was diagnosed with T-LBL. Following the diagnosis, chemotherapy was introduced. The ES was able to secure sufficient tracheal diameter, and ECMO and ventilation were promptly discontinued. In the case of tracheal stenosis from the lower part of the trachea due to anterior mediastinal tumor, depending on the degree of stenosis, VV ECMO can be considered. Moreover, ES can lead to early weaning from VV ECMO and a ventilator.
\end{abstract}

Categories: Emergency Medicine, Pediatrics, Hematology

Keywords: oncologic emergency, airway emergency, endotracheal stent, ecmo, mediastinal t-lbl

\section{Introduction}

Anterior mediastinal tumors can cause respiratory impairment due to airway obstruction, and sedative muscle relaxants can lead to potentially fatal complete tracheal obstruction. Therefore, extracorporeal membrane oxygenation (ECMO) can be considered in cases with lower trachea stenosis. However, complications can increase with prolonged ECMO and ventilation. The introduction of a temporary endotracheal stent (ES) together with ECMO can enable early weaning from ECMO and ventilator.

Here, we report the case of an adolescent male with an airway emergency caused by an anterior mediastinal tumor. A multidisciplinary team collaborated to introduce venovenous (VV) ECMO systematically and immediately inserted an ES to shorten the duration of intensive care.

\section{Case Presentation}

A 15-year-old male presented with dyspnea in the supine position. He had no previous history of tracheomalacia or tracheal stenosis. He was found to have a mediastinal tumor on chest X-ray and was immediately admitted to our hospital. The patient was naturally healthy and had no previous hospitalizations suggestive of tracheomalacia or tracheal stenosis.

On admission, he was $162.5 \mathrm{~cm}$ tall and weighed $45.1 \mathrm{~kg}$. His $\mathrm{SpO}_{2}$ was $98 \%$ on room air, but he presented with orthopnea. Chest radiograph showed enlargement of the upper mediastinum (Figure 1), chest contrastenhanced computed tomography (CT) of the chest demonstrated a $10 \times 7 \times 10 \mathrm{~cm}$ mass in the anterior mediastinum. Moreover, the trachea was highly flattened and compressed by the mass (Figure 2). Blood tests showed elevated lactate dehydrogenase $(763 \mathrm{U} / \mathrm{L})$ and soluble interleukin-2 receptor $(1,024 \mathrm{U} / \mathrm{mL})$, while complete blood counts were normal. The arterial blood gas analysis showed $\mathrm{pH}$ of $7.41, \mathrm{PO}_{2}$ of $116 \mathrm{mmHg}$, $\mathrm{PCO}_{2}$ of $38 \mathrm{mmHg}$, and $\mathrm{HCO}_{3}$ - of $23.7 \mathrm{mEq} / \mathrm{L}$. 


\section{Cureus}

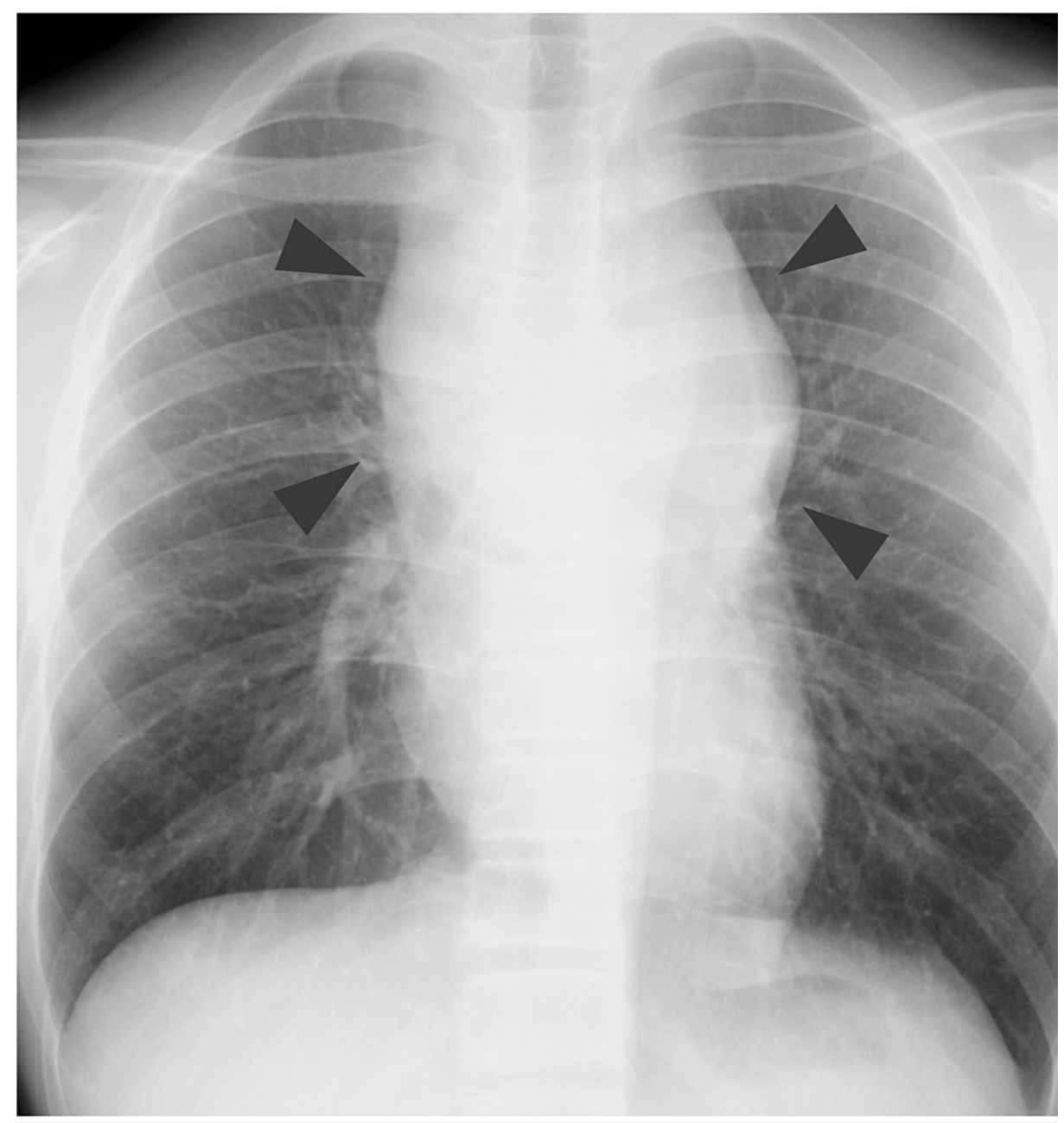

FIGURE 1: Chest X-ray (day 1).

Enlargement of the upper mediastinum (arrowhead) and obscure tracheal shadow can be observed. 


\section{Cureus}

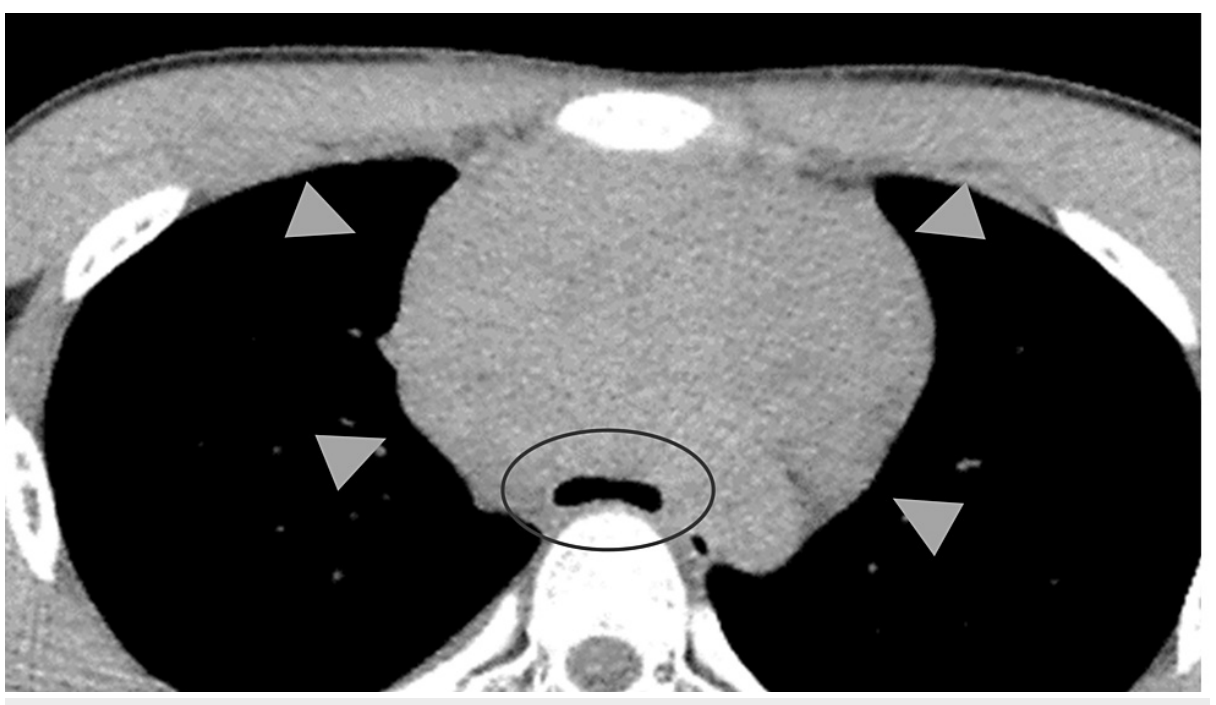

FIGURE 2: Contrast-enhanced CT chest (day 1).

A $10 \times 7 \times 10 \mathrm{~cm}$ sized mass was found in the anterior mediastinum (arrowhead). The tracheal bifurcation was highly flattened (inside the circle).

CT: computed tomography

Due to an airway emergency, the patient was transferred to the intensive care unit (ICU). Because the stenosis extended from the lower part of the trachea to the tracheal bifurcation, ECMO and an ES were prepared as normal tracheal intubation was expected to be difficult. VV ECMO was introduced in the waking state using local anesthesia with dexmedetomidine and pentazocine. Subsequently, 22 and 18-Fr cannula were inserted into the left and right femoral vein for drawing and return, respectively. A BIO CUBE $6000{ }^{\circledR}$ (NIPRO, Osaka, Japan) was used for the oxygenator, and an HLS cannula ${ }^{\circledR}$ (Maquet Getinge, Rastatt, Germany) was used for both devascularization and as a blood sending tube. The initial ECMO blood flow was $3 \mathrm{~L} /$ minute, with a sweep gas flow of $3.0 \mathrm{~L} /$ minute. Due to the planned short-term use of ECMO and the risk of bleeding from the tumor, anticoagulants were not administered. Once ECMO was introduced, we sedated the patient with propofol and rocuronium and performed tracheal intubation. There was no progressive respiratory impairment at this time, and tracheal intubation was performed with no obvious difficulty. A CTguided biopsy and bone marrow examination were then performed, with no worsening of his condition noted. Finally, an ES (AERO ${ }^{\circledR}$ tracheobronchial stent; stent size, $18 \times 60 \mathrm{~mm}$; catalog number, 90123-202; Merit Medical Systems, UT, USA) was placed using a bronchoscope with support by fluoroscopy. While administering muscle relaxants, the airway became completely obstructed, and the $\mathrm{SpO}_{2}$ decreased to $70 \%$; hence, we needed to increase the blood flow of the ECMO. After the ES had been inserted, the patient's respiratory condition immediately stabilized (Figure 3). The time required was one hour for ECMO introduction and thirty minutes each for the CT-guided biopsy and ES insertion. The biopsy revealed a diagnosis of T-lymphoblastic lymphoma (T-LBL). He was sedated in the ICU with midazolam and dexmedetomidine, but no reduced oxygenation was observed. ECMO was weaned off in 23 hours and he was extubated. He left the ICU on day three, and the ES was removed on day 33 (Figures 4, 5). The thrombus in the internal jugular vein, detected on day six, disappeared after 56 days of anticoagulation. The chest CT on day 96 showed remarkable tumor shrinkage (Figure 6) and existence of local tracheal stenosis because of granulation. Chemotherapy for T-LBL was done according to the non-Hodgkin lymphoma-Berlin-FrankfurtMünster-95 protocol. He has completed the chemotherapy protocol and has remained relapse-free for two years. Follow-up chest X-ray every four months has shown improvement in tracheal stenosis from 6 to 9 $\mathrm{mm}$. 


\section{Cureus}

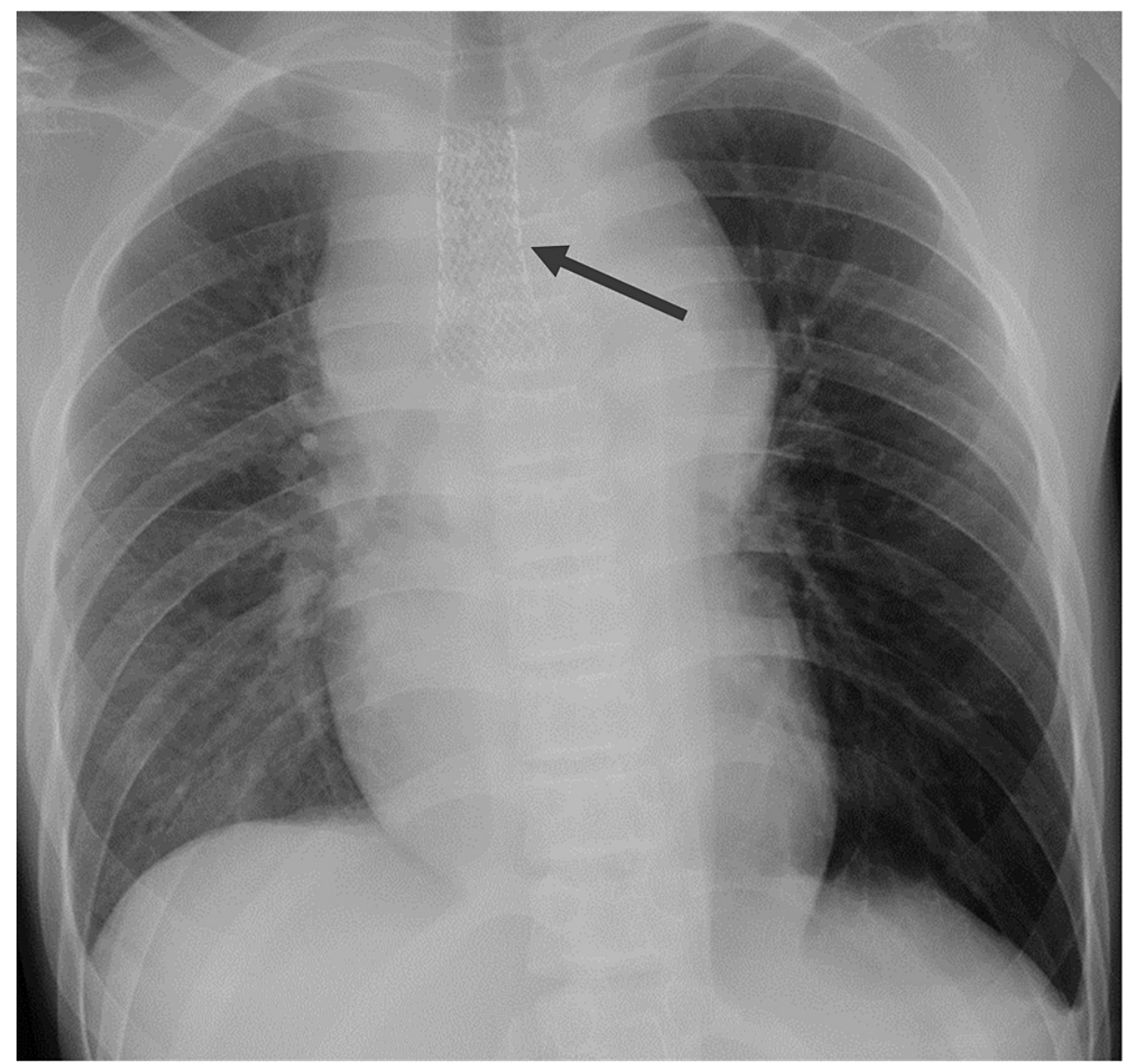

FIGURE 3: Chest X-ray (day 4).

An endotracheal stent was placed in trachea (arrow). 


\section{Cureus}

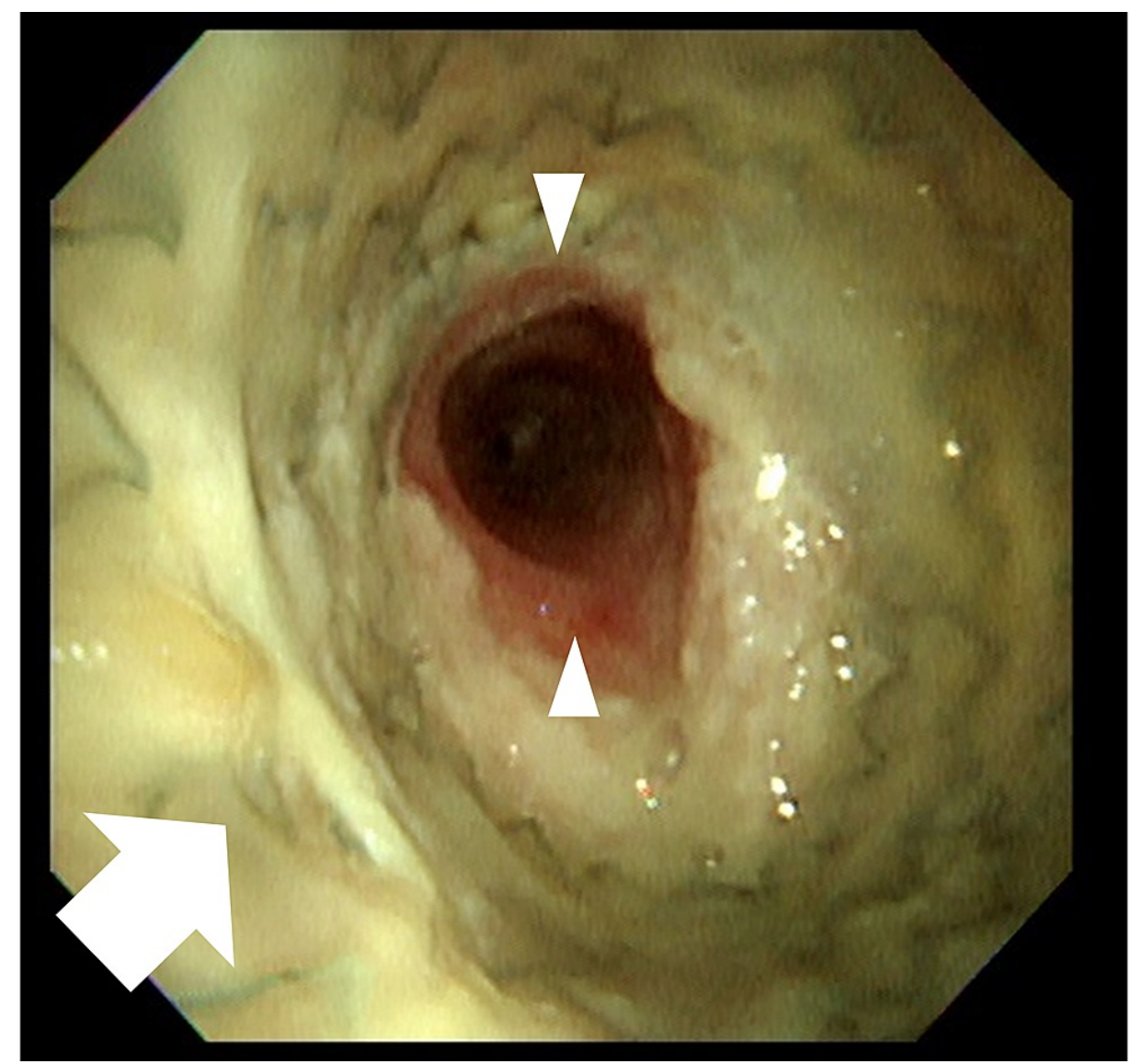

FIGURE 4: The bronchoscopic image of the trachea before ES removal.

An ES (arrow) was properly placed, and the trachea was sufficiently patent (arrowhead). Although sputum adhesion was observed on the surface of the stent, there was no narrowing of the lumen due to it.

ES: endotracheal stent 


\section{Cureus}

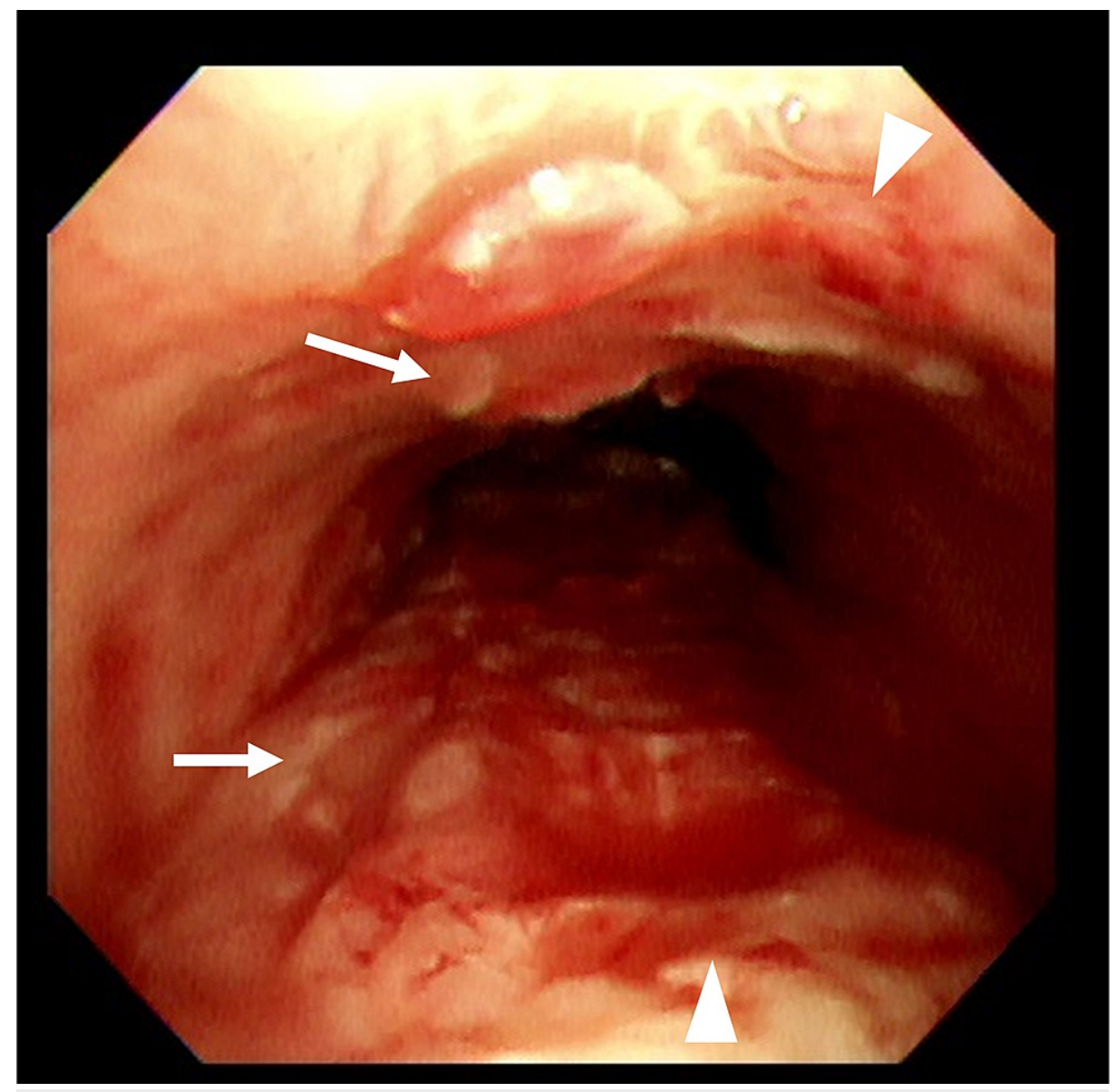

FIGURE 5: The bronchoscopic image of the trachea after ES removal.

Immediately after the removal of ES, a small amount of bleeding (arrow) and localized detachment of the tracheal epithelium (arrowhead) were observed.

ES: endotracheal stent 


\section{Cureus}

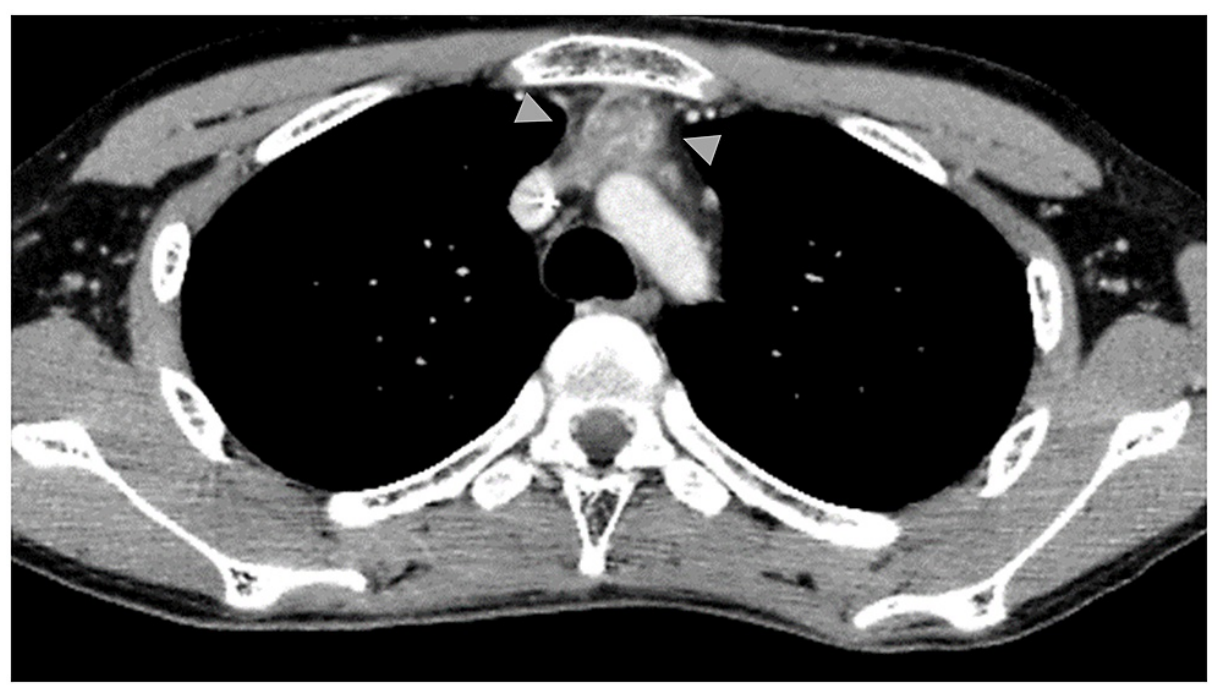

FIGURE 6: Contrast CT of the chest (day 96).

The tumor diameter shrunk to $4.1 \times 2.6 \times 3.8 \mathrm{~cm}$ (arrowhead).

CT: computed tomography

\section{Discussion}

In cases of airway emergencies due to huge anterior mediastinal tumors, especially when the stenosis extends to the bifurcation of the airway, obtaining relief with conventional tracheal intubation can be difficult. In addition, sedation or general anesthesia to obtain biopsy specimens can cause complete airway obstruction. There is reportedly a significant risk of airway obstruction during general anesthesia if the bronchial diameter is competing for more than one-third of the lumen on CT [1]. In such cases, the use of ECMO as a respiratory aid is considered. An ECMO can provide stable circulation; however, complications such as bleeding, embolism, and infection with prolonged ECMO use have been reported [2,3]. In cases of hematological malignancies, early initiation of chemotherapy after a definitive diagnosis is critical to improving survival. An ECMO might be useful as a bridge to chemotherapy in patients with airway emergencies to increase the survival rate for such patients [4]; however, remission-induction chemotherapy causes neutropenia and an immunocompromised state, placing patients at risk of severe infections, such as ventilator-associated pneumonia. In such situations, ES may shorten the intensive care period [5]. Hence, planned ECMO and ES can be appropriate for respiratory management of these cases.

Table 1 summarizes the cases of ECMO in patients with hematological malignancies of the anterior mediastinal [5-15], including the present case, focusing on the intensive care period, airway management, and complications. The stenosis site extended from the lower part of the trachea to the bifurcation or the main bronchus in all cases, suggesting that ECMO introduction might be needed when respiratory management is difficult. Airway management with ECMO included conventional intubation in eight patients and ES in three patients, including our own. The other two patients were managed with ECMO alone. From the viewpoint of safe respiratory management, planned ECMO was performed in four cases, including two cases with ES and two managed with ECMO alone. In the other cases, ECMO introduction was unplanned: tracheal intubation became difficult in five cases, tracheal intubation itself was difficult in two cases, and complete airway obstruction during intubation, decreased oxygenation, and cardiopulmonary arrest during a biopsy occurred in one case each. In patients with planned ECMO, the intensive period, i.e., ventilation and ECMO periods, was shorter than that for unplanned ECMO. The longer the duration of ECMO, the more serious complications tended to be [3]. In addition, the ventilation duration was shorter in ES cases, suggesting that ES may be useful for preventing certain complications, such as ventilatorassociated pneumonia. In two patients who did not require airway management, the duration of ECMO tended to be short, conferring a minimal risk of airway-associated infections; hence, ECMO alone might be suitable for patients without severe airway stenosis. 


\section{Cureus}

\begin{tabular}{|c|c|c|c|c|c|c|c|c|c|c|c|c|c|}
\hline Author & $\begin{array}{l}\text { Leow et al. } \\
\text { [5] }\end{array}$ & $\begin{array}{l}\text { Lueck et al. } \\
\text { [6] }\end{array}$ & $\begin{array}{l}\text { Oto et al. } \\
\text { [7] }\end{array}$ & $\begin{array}{l}\text { Chao et al. } \\
\text { [8] }\end{array}$ & $\begin{array}{l}\text { Huang et al. } \\
\text { [9] }\end{array}$ & $\begin{array}{l}\text { Kim et al. } \\
{[10]}\end{array}$ & $\begin{array}{l}\text { Rotz et al. } \\
\text { [11] }\end{array}$ & $\begin{array}{l}\text { Aboud et al. } \\
\text { [12] }\end{array}$ & $\begin{array}{l}\text { Stewart et al. } \\
\text { [13] }\end{array}$ & $\begin{array}{l}\text { Wickiser et al. } \\
\text { [14] }\end{array}$ & $\begin{array}{l}\text { Wickiser } \\
{[14]}\end{array}$ & $\begin{array}{l}\text { Nokes et al. } \\
\text { [15] }\end{array}$ & $\begin{array}{l}\text { Our } \\
\text { case }\end{array}$ \\
\hline Year of publication & 2021 & 2016 & 2014 & 2006 & 2010 & 2017 & 2020 & 2008 & 1998 & 2007 & 2007 & 2018 & 2022 \\
\hline Age (years)/Sex & 29/M & 20/M & 40/M & $21 / \mathrm{F}$ & 15/M & 20/M & $18 / \mathrm{M}$ & $43 / F$ & 19/M & $11 / \mathrm{M}$ & $4 / \mathrm{M}$ & 49/F & 15/M \\
\hline Disease type & DLBCL & T-LBL & T-LBL & BL & T-ALL & DLBCL & PMBCL & NHL & LBL & T-ALL & T-NHL & MBCL & T-LBL \\
\hline Narrowest part & TBF & Bil-MB & Lt-MB & Bil-MB & Lt-MB & ND & TBF & Lt-MB & TBF & TBF & ND & Bil-MB & TBF \\
\hline Planned ECMO & No & No & No & No & No & No & No & No & No & Yes & Yes & Yes & Yes \\
\hline ECMO type & $V_{A}$ & VA & VA & vV & VA & VA & WV & vV & VA & VA & VA & WV & WV \\
\hline \multirow{2}{*}{$\begin{array}{l}\text { ECMO/Ventilator } \\
\text { period }\end{array}$} & 12 days & 7 days & 6 days & 3 days & 40 hours & 2 days & 40 days & 5 days & 2 days & 5 days & 3 days & 1 day & 23 \\
\hline & ND & 40 days & 28 days & 5 days & 9 days & 59 days & $>40$ days & 13 days & 10 days & None & None & None & 1 day \\
\hline $\begin{array}{l}\text { Airway } \\
\text { management }\end{array}$ & TI & TI & TI & $\begin{array}{l}\text { TI (ES } \\
\text { unsuccess) }\end{array}$ & $\mathrm{TI} \rightarrow \mathrm{ES}$ & TI & $\begin{array}{l}\mathrm{Tl} \text { (ES } \\
\text { migration) }\end{array}$ & $\begin{array}{l}\text { TI (ES } \\
\text { unsuccess) }\end{array}$ & $\mathrm{TI}$ & CPAP (Heliox) & (Heliox) & CPAP $\rightarrow E S$ & $\mathrm{TI} \rightarrow \mathrm{ES}$ \\
\hline $\begin{array}{l}\text { Complications of } \\
\text { ECMO }\end{array}$ & ND & $\mathrm{Htx}, \mathrm{Pn}$ & $\begin{array}{l}\text { Skin } \\
\text { abscess }\end{array}$ & None & None & ND & $\begin{array}{l}\text { SVC } \\
\text { syndrome }\end{array}$ & None & $\begin{array}{l}\text { Lt-femoral } \\
\text { ischemia }\end{array}$ & None & $\begin{array}{l}\text { Lower limb } \\
\text { VT }\end{array}$ & None & VT \\
\hline
\end{tabular}

TABLE 1: A literature review of cases of ECMO in patients with hematological malignancies of the anterior mediastinal.

ALL: acute lymphoblastic leukemia; Bil: bilateral; BL: Burkitt Lymphoma; CPAP: continuous positive airway pressure; CR: complete response; ECMO: extracorporeal membrane oxygenation; ES: endotracheal stent; F: female; Htx: hemothorax; LBL: Lymphoblastic lymphoma; Lt: left; MBCL: mature B-cell lymphoma; M: male; MB: main bronchus; ND: not described; NHL: non-Hodgkin lymphoma; PMBCL: primary mediastinal B-cell lymphoma; Pn: pneumonia; PR: partial response; TBF: tracheal bifurcation; TI: tracheal intubation; SVC: superior vena cava; VA: venoarterial; VT: venous thrombosis; VV: venovenous

In cases of hematologic malignancies, tumors may shrink rapidly with induction treatment; however, malignant lymphoma without tumor reduction for more than one month has been reported [9]. Therefore, if the degree of stenosis is severe, ES may be considered in addition to planned ECMO. Furthermore, in cases with successful ES, two of three patients were planned to receive ECMO, whereas all failed ES cases were treated with unplanned ECMO. Cases with stenosis in the lower part of the trachea can be safely managed by the planned introduction of ECMO [1], and ES may not fail. However, there are limitations of ES, such as the granulation of the trachea. Only a few reports have described ES for airway emergencies caused by hematological malignancies, and the timing of ES removal needs to be studied further with more cases. In addition, ES is contraindicated if a nonviable lung is present beyond the obstruction, or when vascular exclusion occurs $[16,17]$. We also need to be aware of the history of tracheal stenosis or tracheomalacia which makes the introduction of ES difficult. In these cases, it is necessary to increase the flow rate of ECMO to maintain oxygenation.

Furthermore, in this case, anticoagulant therapy was not performed when ECMO was used, resulting in the formation of a thrombus in the internal jugular vein; however, the thrombus disappeared by the following therapy. Hence, we conclude that the advantage of not using anticoagulants surpasses the risk of fatal airway bleeding during ECMO.

\section{Conclusions}

Reviewing our experience and previous reports, we found that in airway emergencies caused by anterior mediastinal masses, it may be difficult to secure an airway by tracheal intubation alone, depending on the site and degree of airway stenosis. The planned introduction of ECMO in patients with a mediastinal mass caused by hematological malignancies can be considered, depending on the site of airway stenosis and stenotic degree (>50\%), to allow respiratory management to be performed safely. In addition, ES can be considered as an option to prevent ECMO complications.

\section{Additional Information}

\section{Disclosures}

Human subjects: Consent was obtained or waived by all participants in this study. Conflicts of interest: In compliance with the ICMJE uniform disclosure form, all authors declare the following: Payment/services 
info: All authors have declared that no financial support was received from any organization for the submitted work. Financial relationships: All authors have declared that they have no financial relationships at present or within the previous three years with any organizations that might have an interest in the submitted work. Other relationships: Grant: Souichi Suenobu Grants-in-Aid for Scientific Research (Kakenhi) 18K07822 and 21K07866. Employment: Souichi Suenobu General Pediatrics and Emergency Medicine (Oita City).

\section{Acknowledgements}

We thank the patient's parents for providing their informed consent for the publication of this case. We also thank Dr. Yuka Kimura, Naoki Hirano, Hironori Goto, and Shuji Kuga for their clinical support, and Brian Quinn (Japan Medical Communication) for editing this manuscript.

\section{References}

1. Goh MH, Liu XY, Goh YS: Anterior mediastinal masses: an anaesthetic challenge. Anaesthesia. 1999, 54:6704. 10.1046/j.1365-2044.1999.00961.x

2. Wohlfarth P, Ullrich R, Staudinger T, et al.: Extracorporeal membrane oxygenation in adult patients with hematologic malignancies and severe acute respiratory failure. Crit Care. 2014, 18:R20. 10.1186/cc13701

3. Dalton HJ, Reeder R, Garcia-Filion P, et al.: Factors associated with bleeding and thrombosis in children receiving extracorporeal membrane oxygenation. Am J Respir Crit Care Med. 2017, 196:762-71. 10.1164/rccm.201609-19450C

4. Tathineni P, Pandya M, Chaar B: The utility of extracorporeal membrane oxygenation in patients with hematologic malignancies: a literature review. Cureus. 2020, 12:e9118. 10.7759/cureus.9118

5. Leow L, Sampath HK, Yong KJ, et al.: Rescue extracorporeal membrane oxygenation for massive anterior mediastinal masses. J Artif Organs. 2021, 24:450-7. 10.1007/s10047-021-01264-6

6. Lueck C, Kuehn C, Hoeper MM, Ganser A, Eder M, Beutel G: Successful use of extracorporeal membrane oxygenation during induction chemotherapy in a patient with mediastinal tumor mass of a T lymphoblastic lymphoma. Ann Hematol. 2016, 95:1719-21. 10.1007/s00277-016-2734-7

7. Oto M, Inadomi K, Chosa T, Uneda S, Uekihara S, Yoshida M: Successful use of extracorporeal membrane oxygenation for respiratory failure caused by mediastinal precursor T lymphoblastic lymphoma. Case Rep Med. 2014, 2014:804917. 10.1155/2014/804917

8. Chao VT, Lim DW, Tao M, Thirugnanam A, Koong HN, Lim CH: Tracheobronchial obstruction as a result of mediastinal mass. Asian Cardiovasc Thorac Ann. 2006, 14:e17-8. 10.1177/021849230601400224

9. Huang YL, Yang MC, Huang $\mathrm{CH}$, et al.: Rescue of cardiopulmonary collapse in anterior mediastinal tumor: case presentation and review of literature. Pediatr Emerg Care. 2010, 26:296-8. 10.1097/PEC.0b013e3181d6daf0

10. Kim K, Kim S, Lee JW, Yoon JS, Chung NG, Cho B: Prognostic factors of ICU mortality in pediatric oncology patients with pulmonary complications. J Pediatr Hematol Oncol. 2020, 42:266-70. 10.1097/MPH.0000000000001616

11. Rotz SJ, Almeida FA, Koyfman S, et al.: Continuous infusion chemotherapy, radiotherapy, and FDG-PET are feasible during extracorporeal membrane oxygenation. Pediatr Blood Cancer. 2020, 67:e28429. 10.1002/pbc.28429

12. Aboud A, Marx G, Sayer H, Gummert JF: Successful treatment of an aggressive non-Hodgkin's lymphoma associated with acute respiratory insufficiency using extracorporeal membrane oxygenation. Interact Cardiovasc Thorac Surg. 2008, 7:173-4. 10.1510/icvts.2007.159921

13. Stewart AS, Smythe WR, Aukburg S, Kaiser LR, Fox KR, Bavaria JE: Severe acute extrinsic airway compression by mediastinal tumor successfully managed with extracorporeal membrane oxygenation. ASAIO J. 1998, 44:219-21. 10.1097/00002480-199805000-00018

14. Wickiser JE, Thompson M, Leavey PJ, Quinn CT, Garcia NM, Aquino VM: Extracorporeal membrane oxygenation (ECMO) initiation without intubation in two children with mediastinal malignancy. Pediatr Blood Cancer. 2007, 49:751-4. 10.1002/pbc.20741

15. Nokes BT, Vaszar L, Jahanyar J, Swanson KL: VV-ECMO-assisted high-risk endobronchial stenting as rescue for asphyxiating mediastinal mass. J Bronchology Interv Pulmonol. 2018, 25:144-7. 10.1097/LBR.0000000000000435

16. Ernst A, Silvestri GA, Johnstone D: Interventional pulmonary procedures: guidelines from the American College of Chest Physicians. Chest. 2003, 123:1693-717. 10.1378/chest.123.5.1693

17. Chin CS, Litle V, Yun J, Weiser T, Swanson SJ: Airway stents. Ann Thorac Surg. 2008, 85:S792-6. 10.1016/j.athoracsur.2007.11.051 